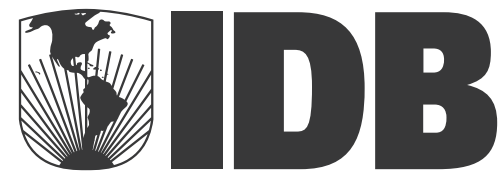

Development Effectiveness

Impact-Evaluation Guidelines

Technical Notes

No. IDB-TN-398

April 2012

\title{
Indicators to Assess the Effectiveness of Climate Change Projects
}

Nancy McCarthy Paul Winters Ana Maria Linares Timothy Essam 
This page has been intentionally left blank. 


\section{Indicators to Assess the Effectiveness of Climate Change Projects}

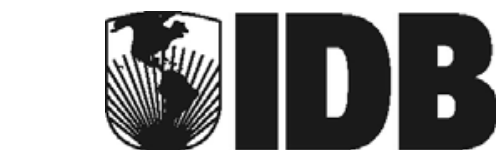

Inter-American Development Bank 2012 
http://www.iadb.org

The Inter-American Development Bank Technical Notes encompass a wide range of best practices, project evaluations, lessons learned, case studies, methodological notes, and other documents of a technical nature. The information and opinions presented in these publications are entirely those of the author(s), and no endorsement by the Inter-American Development Bank, its Board of Executive Directors, or the countries they represent is expressed or implied.

This paper may be freely reproduced.

Nancy McCarthy. President LEAD Analytics, Washington, DC. nmccarthy@leadanalyticsinc.com 


\title{
Indicators to Assess the Effectiveness of Climate Change Projects
}

\author{
Abstract \\ Nancy McCarthy, ${ }^{1}$ Paul Winters, ${ }^{2}$ Ana Maria Linares, ${ }^{3}$ Timothy Essam ${ }^{4}$
}

Determining reasonable indicators for climate change projects is complicated by the long-term horizon of both mitigation and adaptation project impacts as well as the uncertainty associated with climate change impacts. Actions taken now are often designed to have an impact in the uncertain and distant future and may not directly mitigate or adapt to climate change, but be taken as a step to prepare for future actions. Further complicating identification of indicators is the fact that there is a spectrum of projects, from the pure climate change-focused projects to those that provide climate change benefits as one part of an overall development program, and finally to those with only incidental indirect effects. The objective of this document is to discuss SMART (Specific, Measurable, Achievable, Realistic and Timely) indicators that can be used for assessing the impact of climate change projects, including those that seek to adapt to the expected impacts of climate change and those that promote low carbon emissions growth strategies to mitigate greenhouse gases.

JEL Classification: H43, Q54, Q56, Z18

Keywords: climate chance, indicators, development effectiveness, impact evaluation

1 President LEAD Analytics, Washington, DC. nmccarthy@leadanalyticsinc.com

2 Associate Professor. Department of Economics, American University, Washington, DC. winters@american.edu

3 Sector Lead Specialist. Office of Strategic Planning and Development Effectiveness. Inter-American Development Bank, Washington, DC. anamarili@iadb.org

${ }^{4} \mathrm{PhD}$ Candidate. Agricultural and Resource Economics. University of Maryland, College Park, MD. tessam@arec.umd.edu 


\section{Table of Contents}

1. Introduction 3

2. Challenges in Identifying Climate Change Indicators for the IDB 3

2.2 Development and Additionality 4

2.2 Addressing Climate Change 5

$\begin{array}{lr}2.3 \text { Identifying Indicators } & 8\end{array}$

3. Indicators for Examining Projects Related to Adaptation 9

$\begin{array}{ll}\text { 3.1 Stages of Adaptation Projects and Indicators } & 10\end{array}$

3.2 Developing Adaptation Indicators, Some Examples 14

3.2.1 Outputs and Outcomes from Initial Stages $\quad \mathbf{1 4}$

4. Indicators for Examining Projects Related to Mitigation 17

$\begin{array}{ll}\text { 4.1 Stages of Mitigation Projects and Indicators } & 20\end{array}$

4.2 Developing Mitigation Indicators and Some Examples from Current Projects 22

5. Potential Pitfalls and “Indicators" to Avoid 25

$\begin{array}{ll}5.1 \text { Specific } & 25\end{array}$

$\begin{array}{ll}5.2 \text { Measurable } & 27\end{array}$

$\begin{array}{lr}5.4 \text { Achievable } & 29\end{array}$

5.4 Relevant $\quad 29$

$\begin{array}{ll}5.5 \text { Timely } & 30\end{array}$

$\begin{array}{ll}\text { 6. Conclusions } & 31\end{array}$

$\begin{array}{ll}\text { References } & 32\end{array}$ 


\section{Introduction}

The Inter-American Development Bank's (IDB) Ninth General Capital Increase sets a target of $25 \%$ of total lending to support climate change initiatives, sustainable energy and environmental sustainability. This is a substantial increase from the 2006-2009 target of 5\% of lending to these areas and is to be achieved by 2015. The new target will lead to increased lending in these areas, particularly in climate change projects.

In order to ensure that the increase in spending on climate change is effective at bringing about development, it is necessary to carefully design monitoring and evaluation systems that not only ascertain the actions taken as part of projects, but also identify the impact of the projects. A key part of a good monitoring and evaluation system is to have quantifiable indicators that are SMART (Specific, Measurable, Achievable, Realistic and Timely). The objective of this document is to discuss indicators that can be used for assessing the impact of climate change projects, including those that seek to adapt to the expected impacts of climate change and those that promote low carbon emissions growth strategies to mitigate greenhouse gases.

Determining reasonable indicators for climate change projects is complicated by the long-term horizon of both mitigation and adaptation projects as well as the uncertainty associated with climate change impacts. Actions taken now are often designed to have an impact in the uncertain and distant future. Additionally, current actions may be taken not to directly mitigate or adapt to climate change, but as a step to prepare for future actions that achieve the ultimate objectives of mitigation and adaptation; the latter is often the case for climate change policybased loans. For this reason, before discussing indicators in detail, Section 2 discusses the specific challenges of identifying climate change indicators with specific reference to how the IDB manages projects and the overall climate change strategy. This is followed by a discussion of indicators that can be used for projects focusing on mitigation in Section 3 and then, in Section 4, those that can be used for adaptation projects.

\section{Challenges in identifying climate change indicators for the IDB}

To address the long-term and uncertain nature of climate change impacts, the IDB has developed a Climate Change Strategy to identify courses of action for assisting borrowing countries in addressing climate change concerns. While the strategy must maintain a long-term vision of how to address climate concerns, the nature of development banks is that their loan operations tend to 
be short-term, about two to six years, and target a wide range of sectors. An initial key challenge in any attempt to develop indicators is how to determine what intermediate indicators suggest long-term success in addressing climate change. What is required are metrics that are indicative of clear progress being made towards long-term mitigation and adaptation objectives. In this section, we consider these challenges first addressing this issue of what constitutes a climate change project and then how to address climate change in the long term within the context of IDB procedures for evaluating loan performance.

\subsection{Development and Additionality}

Part of the challenge, particularly with respect to adaptation, is that the ability to address climate change is reflected in a country's level of development. In general, the more developed a country, the more resilient it is likely to be to climate change. Providing funds that assist in the development of a country could potentially be viewed as supporting climate change adaptation. The link between development and the ability to address climate change creates a risk that existing development projects will simply be repackaged as climate change projects, resulting in little new action. While overall development plays an important role in addressing climate concerns, clearly the point of having a specific strategy is to take additional actions to deal with climate-related issues. As such, the IDB's climate change strategy and projects it prioritizes, and the corresponding indicators of success of those projects, will seek to provide additionality - that is, will take actions beyond what is already done.

To consider more carefully the issue of additionality, three types of projects that relate to climate change can be identified. The first type, which might be called direct projects, consists of those projects specifically addressing climate concerns. These are projects that are designed explicitly to mitigate greenhouse gas emissions, to adapt to anticipated changes in climate, or to take the steps necessary to meet those objectives, such as obtaining the necessary information on climate risks, identifying the most cost-effective means to mitigate greenhouse gases (GHGs), or setting up the institutional structures and mechanisms that enable government bodies to effectively address climate change in an integrated and coherent manner. In this case, indicators should be included that either show direct impact on adaptation or mitigation, or progress towards reaching those goals. 
The second type of project includes those that have a broader development agenda, but have clear mitigation or adaptation components in addition to the broader agenda-additional projects. For example, as one component of an overall tourism strategy, a tourism project may create a national park that may have the climate benefit of reducing deforestation. An agricultural project may promote crop and land management practices that reduce long-term vulnerability to climate change, but also improve short-term profitability. A reform of the electricity generation and distribution system may include a combination of actions designed to improve the efficiency of the system as well as actions that lead to investments that reduce emissions (relative to what would have been done otherwise). Although not the sole focus of the project, in these cases there are actions that clearly link to climate change and that provide additionality. Of course, if a project claims additionality in terms of benefits addressing climate concerns, the project monitoring and evaluation system should include indicators explicitly measuring these benefits.

The final type of project comprises those in which benefits for mitigation or adaptation to climate change are incidental or "serendipitous". These serendipitous projects include many general development projects as well as specific ones, particularly in the areas of agriculture, energy, transport, tourism, etc. While such projects may have incidental climate change benefits, to the extent that they would have been undertaken without any change whatsoever in design, evaluation or implementation, they would not provide additionality. In general, if no climate change-specific outputs or outcomes are identified outside of general development, then clearly one cannot identify corresponding SMART indicators.

Of course, there will be a spectrum of projects from the pure climate change-focused projects to those with only incidental indirect effects. If a project claims climate change-related benefits, those should be measured as one of the indicators identified to determine the project's development effectiveness.

\subsection{Addressing Climate Change}

Beyond identifying climate change outputs and outcomes within the scope of the project, another challenge to identifying indicators relates to the long-term nature of climate change and thus the time horizon required for addressing it. Given the relatively short-term horizon of development projects, it is likely to make sense to view each project as part of the incremental steps a country makes to address climate change. Each country must determine the set of activities that are 
necessary to address climate change and order them in a manner that ensures progress is being made towards the ultimate goals of adapting to changes in climatic conditions and mitigating GHGs. In order to see how IDB projects might fit into this country-level planning, we consider the set of activities required for such planning.

For a country initiating a climate change adaptation and mitigation strategy, four sets of activities or "stages" that will lead to an increased ability to mitigate GHGs and adapt to climate change (see Figure 1) are envisioned. The first two stages are closely inter-related; the collection of information needed to evaluate how different projects and investments will fare in the face of climate change, and the development of national capacity to analyze that information. To address climate concerns, information is required on the sources of GHGs and potential impacts of changing climatic conditions on weather patterns, sea rise, glacial melt, etc. Correspondingly, information needs to be systematically analyzed to understand what is happening and what potential responses can be taken. The collection of information and capacity to analyze that information lays the groundwork for future country-level activities.

\section{Figure 1: Addressing Climate Change}

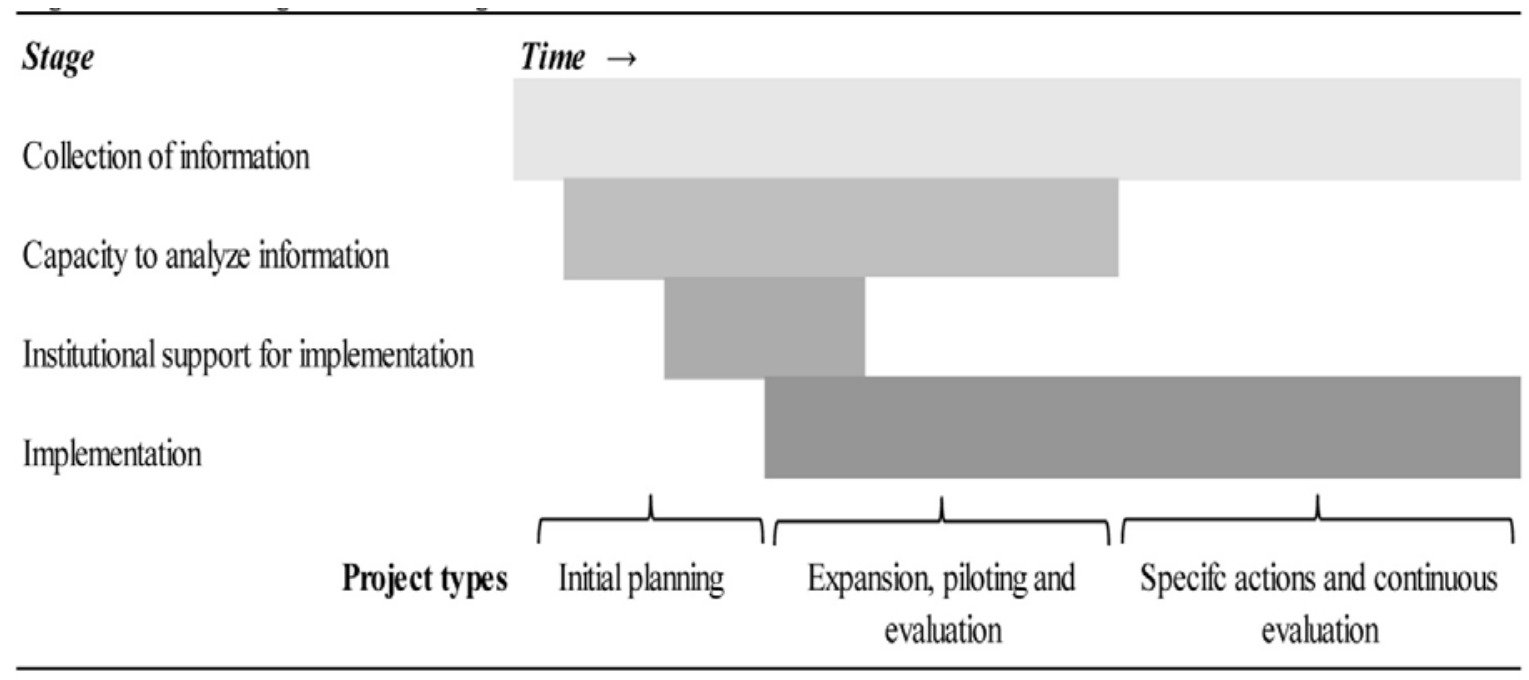

The third stage, which may occur concurrently with the first two, includes a wide range of activities focusing on building institutional capacity to effectively address climate change. This can include building technical capacity for using the analyses to prioritize and implement mitigation and adaption actions at the national, sub-national and local levels. It may also include designing appropriate institutional structures and coordination mechanisms to ensure consistency 
and coherence in implementing the strategy across the many relevant line ministries and administrative levels. Finally, it can include reviewing the existing legal and regulatory framework, determining whether changes need to be made, and in designing and adopting new laws and regulations, where necessary.

The fourth stage is then implementing responses to climate change starting with pilot projects and then longer-term investment projects in the different sectors. These stages are discussed in more detail in the subsequent sections on mitigation and adaptation.

For a country to proceed through these stages, careful planning is required, from developing a climate change strategy, to creating a road map for taking action, and finally taking action. Actions to be taken to address climate change should be founded on an analysis of rigorously collected data and have an institutional structure that allows for careful consideration of the best set of actions to take and to monitor and evaluate those actions to ensure they were successful or if not, why they were not.

From the IDB's perspective, where to start in the process depends on what actions have already been initiated in the country and where the country stands in each of these stages. The IDBs approach to doing technical cooperations (TCs) and loan projects over relatively short periods of time and separately across sectors necessarily requires dividing activities into distinct projects. Figure 1 summarizes how the stages of addressing climate change fits with the IDB approach to supporting development, dividing TCs and loan projects into three types: (i) initial planning, (ii) expansion, piloting and evaluation; and (iii) specific actions and continuous evaluation.

For countries that remain at early stages of climate change actions, presumably the first set of projects are likely to include the first two stages noted above (information gathering and capacity building for analysis) as well as the third stage of institutional development. If a TC is used, it may only address one of the stages while if loans are used, it is likely to include multiple stages. Regardless of the approach, these operations help generate the necessary information to address climate concerns, analyze that data, and take steps to create the institutional structures to use that information to develop an initial plan of action. Identifying indicators of the success of operations linked to these stages are a challenge given that they are not designed to directly address climate concerns, but to lay the groundwork to do so. 
The second set of IDB operations are likely to move beyond focusing on preparing to address climate change to taking initial actions to mitigate GHG emissions and adapt to climate changes as determined by the strategies and plans determined in the initial projects. As such they are less likely to be TCs but loan projects. Presumably, these projects would include pilot projects in both mitigation and adaptation with specific climate change-linked objectives and indicators that identify whether those objectives are met. Of course, these projects would also involve continued information gathering and capacity building. Over time, the expectation is that an increasing emphasis will be placed on obtaining information and developing capacity to evaluate climate change projects to determine what works and achieves identified objectives and what does not.

The last set of IDB-supported projects would then involve more large scale projects at the national, regional and sectoral level. Since these involve broader projects and actions, the associated indicators would presumably measure the ultimate objectives of a climate change plan of action; namely, those linked to mitigation and adaptation. In some cases, these indicators may be measures directly linked to climate change, such as reduced GHG emissions or reduction in indicators of vulnerability, while in others they would be indirect measures, such as changes in forest cover that are clearly linked to climate change.

\subsection{Identifying Indicators}

As noted, some countries are likely to be further along than others. The appropriate set of indicators for a given project depends on what stage a country is at and the types of TCs and loan projects being implemented.

Because of these factors, evaluating the success of an individual climate change project is challenging. As with any development project funded by the IDB, the indicators for an individual project must be SMART and vertically logical—going from inputs, to outputs, to outcomes and finally to impacts. For the reasons noted above, understanding the set of indicators included in an individual project is difficult unless presented in the broader context of the country's long-term climate change plan. This is true of pure climate change projects, which should advance the overall climate agenda, as well as mixed development-climate projects which include a welldefined climate change sub-component.

In any case, the functional relationship between indicators and both project and ultimate objectives need to be well articulated. This is important for technical cooperations, and 
particularly important for policy based loans. Policy based loans have an additional "Policy Matrix”, which has indicators to measure whether certain policy activities have led to identified outputs. The trick here is to be very specific about the links between policy outputs and the outcomes and impacts found in the Results Matrix. The logic of the text should make clear how policy related activities relate to the outcomes that are specified in the Results Matrix, and the respective indicators should capture whether the policy-based outputs led to outcomes and longterm impacts.

In the next section, we discuss indicators for climate change adaptation projects following the four stages developed above, and end the section with examples of indicators for outputs and outcomes. In the fourth section, we discuss indicators for mitigation projects. Since the first three stages related to mitigation are similar to those for adaptation, at the end of mitigation section, we focus on developing indicators for the final "implementation" stage, primarily because there are already mitigation projects up and running. In the fifth section, we discuss "pitfalls" that project developers often run into when constructing indicators, and provide examples from existing projects and programs to highlight these problems. Concluding comments are provided in the sixth section.

\section{Indicators for Examining Projects Related to Adaptation}

Climate change is predicted to alter mean temperatures and precipitation in the longer run, but is also expected to lead to greater climate variability in the short- to medium-term. There is still a great deal of uncertainty regarding likely changes in both the mean and the variability of both temperature and precipitation, though likely scenarios for changes in mean temperature are more certain, at least at coarse levels (IPCC, 2007; Parry et al., 2007; Rosenzweig \& Tubiello, 2006). Following the IPCC definition, "adaptation to climate change refers to adjustment in natural or human systems in response to actual or expected climatic stimuli or their effects, which moderates harm or exploits beneficial opportunities" ${ }^{5}$. Adaptive capacity, according to the IPCC, is the "ability of a system to adjust to climate change, including climate variability and extremes, to moderate potential damages, to take advantage of opportunities, or to cope with the consequences.” In the shorter term, countries are likely to focus on increasing adaptive capacity in order to mitigate damages associated with increased variability and extremes.

\footnotetext{
${ }^{5}$ The glossary can be found at: http://www.ipcc.ch/pdf/glossary/tar-ipcc-terms-en.pdf
} 
At the same time, many observers have noted that many countries are already vulnerable to shocks, either to price shocks, non-climate-related disasters (e.g. earthquakes, volcanic eruptions), and to climate-related disasters. This current vulnerability is often termed an “adaptation-deficit” (Parry et al., 2007; Burton, 2004). As many observers have noted, reducing vulnerability and increasing system resilience makes it difficult to separate "development” from actions taken specifically to address climate change. If we consider the trichotomy of potential projects developed in section 2 (direct, additional, serendipitous), projects that aim to increase the ability to address adaptation deficits directly linked to climate-related disasters are likely to fall within the additional category.

\subsection{Stages of Adaptation Projects and Indicators}

Considering the stages noted in Table 1, we first jointly consider collection of information (stage 1) and analyses (stage 2). Because of the uncertainty surrounding climate change, initial adaptation projects will likely be aimed at identifying key sectors and/or geographic regions that are predicted to suffer most from any change in climate. To do this may mean downscaling existing global climate models, coupling these with hydrological or other bio-physical process models, and generating scenarios that also incorporate socio-economic information. This type of scenario analysis allows policymakers and investors to consider how any one type of project might fare under the range of likely climate outcomes. This differs from relying on past events only, in that information on potential future events, which can differ from the past events, is incorporated to give a richer risk profile of the investment. As an example of a directly climate change-relevant investment, consider coastal zones with the necessary infrastructure to currently cope with tidal waters. These zones may still be vulnerable to any changes in water levels and flows outside of historic experience; a risk analysis would help clarify the reinforcements necessary to manage climate change-related increases in the risk of flooding and degradation of the coastal zone. As an example of an additionality project, consider a region heavily dependent on rainfed agriculture that already suffers from intermittent hurricanes and where new investment is being considered. Additionality can be captured by scenario analysis that incorporate best available evidence on likely climate changes. For example, it may be used to evaluate different irrigation infrastructure specifications in terms of flexibility to respond to a wider range of climate realizations. Or, it may be used in valuing greater reductions in production risk from various seeds, given potential climate realizations. 
The above examples focus on information collection and capacity to analyze data, the outputs are datasets and capacity to use that data to evaluate different investments and policies. The outcome is that the knowledge generated based on this information and capacity is used to guide and prioritize public policy, as well as public and private investments, to increase the ability of the country, its sub-national governments, its sectors and its people to manage climate variability and to adapt to longer-term climate change trends (thus, it is an input into stages 3 and ultimately 4). The broad impact is that national, sub-national, local and household goals for development are not imperiled by climate change.

The third stage is to build institutional framework, or the "enabling” framework, to support adaptation and improved adaptive capacity at all relevant levels. This is perhaps one of the more difficult types of project for which to develop SMART indicators. In this case, then, it is best to disaggregate the type of institutional capacity that the project focuses on. Such projects often focus on the legal framework, on institutions to disseminate information and obtain feedback, on developing institutions that respond to climate change shocks, on promoting adaptation and flexibility in the longer term, and developing linkages across relevant stakeholders and scales to enable efficient and equitable responses to climate change. In terms of the legal framework, examples would include drafting and enforcing regulations related to building codes updated to reflect potential climate change, alterations in land use and zoning restrictions, and, in some cases, clarification of the bundle of real property rights. It would also include ensuring that such sector-specific laws and regulations were harmonized and consistent across sectors.

The above would be direct climate change projects. Institutional projects might also have additional climate change sub-components. For instance, a project might focus on restructuring social safety net programs, with a specific sub-component focusing on responsiveness to increased frequency of climate shocks (Parry et al., 2009; Heltberg, 2009). Or, a project focusing on improving the effectiveness of rural extension might include a sub-component that addresses the capacity of the extension system to develop climate change-relevant materials, and the ability to disseminate such information.

Finally, adaptation projects often include activities to strengthen institutional capacity to develop effective linkages and communications pathways across different relevant actors. These can include linking local, sub-national and national government agencies (vertical), linking 
across different government agencies at the various levels (horizontal), or linking different types of actors (civil society organizations, local government and research institutes).

The above examples focus on projects aimed at building institutional frameworks and mechanisms to address climate change adaptation, and the main output is increased capacity to implement adaptation and adaptive capacity actions. The outcome is that institutions effectively implement a climate change strategy that comprehensively addresses climate change adaptation, that information is broadly shared across relevant stakeholders, that all levels of government effectively respond to climate-driven shocks, and that linkages developed among different actors lead to greater adaptive capacity and wider potential to adapt to climate change across sectors and geographic regions.

The fourth stage focuses on operationalizing actions to support adaptation and improve adaptive capacity. While developing indicators for such projects are easier than for the knowledge and institutional capacity building projects mentioned above, they also cover a wide range of sectors, including agriculture, forestry, coastal zone management, health systems, buildings, transportation and energy. Second, many of these projects will fall into the second category of additional projects enumerated above - those with broad development goals but which also have a specific adaptation component. Clarity in identifying the additionality of incorporating climate change adaptation component is required in order to develop SMART indicators. For instance, the design and implementation of a soil and water conservation project for farmers under existing conditions may well differ from both design and implementation when considering potential future climate scenarios. Similarly, a public health project addressing vector borne diseases may include an additional component to include information on potential changes in the vectors' geographical distribution. A buildings or transportation project may include an additional component to evaluate optimal design and materials when incorporating potential future climate stresses.

In other cases, an adaptation may be realized from an existing project proposal without any specific adaptation component -the serendipitous projects mentioned above. In other words, development benefits and adaptation benefits are joint products from the same project. Depending on the project, it may still be relevant to develop indicators of this additional benefit; documenting such benefits will help in prioritizing future allocations and in preparing costbenefit or cost-effective analyses where these will be undertaken. Many current projects also 
have activities that (it is hoped) yield multiple benefits, for instance many sustainable land management techniques are already expected to generate both economic and environmental benefits. Such techniques may also increase adaptive capacity directly through improved soil structure and soil moisture management, reducing yield losses in extreme weather event years. The latter is an example that is a bit "more" than serendipitous, but less than a clear stand-alone sub-component and highlights that there are really a range of project types. One way to consider where on the spectrum the adaptation falls is to consider whether there is a direct adaptation benefit (improved soil stability=improved adaptive capacity), or whether the benefit is very indirect, e.g. expanded rural labor employment opportunities outside of agriculture (increased access to more stable and diverse income sources enables households to absorb shocks no matter what the source -droughts and floods, but also illness, earthquakes, crime).

Another related issue concerns the construction of baseline scenarios. Baselines can be tricky when the benefits are realized over long time periods. With actions that directly affect adaptation and that require costly outlays, then the assumption that the project's outputs would not be generated in the absence of project is generally justifiable. However, with actions that have co-benefits, it is more difficult to determine how the future would unfold in the absence of the adaptation project, since resources may already be dedicated to capture the co-benefits, making constructing a "business as usual” scenario more difficult. The latter is closely linked with the concept of additionality in mixed development/adaptation projects. ${ }^{6}$ Additionally, the direct benefits are often reduced damages. The baselines and "business as usual" scenarios must then be able to capture higher damages that would occur in the absence of the project; that is, negative impacts would be dampened, but often still negative. In certain cases, it may be relatively easy to measure current and future damages in the absence of a project, e.g. using current information on mortality or property damage trends.

The number of direct adaptation projects with clear indicators is limited making it difficult to provide specific examples of actual projects with SMART indicators. Instead, in the section below, we provide a few examples of output and outcome indicators that are illustrative of some of the projects we discussed above.

\footnotetext{
${ }^{6}$ With purely serendipitous projects, the baseline and "business as usual" to capture future time periods reflects changes that would occur with projects whose objectives are to achieve different goals from climate change adaptation (e.g. increase resilience to climate change shocks, improve disaster preparedness, both with respect to current climate conditions).
} 


\subsection{Developing Adaptation Indicators, Some Examples}

The specific indicators to be included in an IDB project depend on whether they are TCs, policybased loans or investment loans, and whether they involve individual or multiple stages and which stages are included. In the following, we present some examples of projects for each of the four stages, recognizing that many projects will include two or three stages.

\subsubsection{Outputs and Outcomes from Initial Stages}

1. Project to collect data required to perform vulnerability assessments to droughts and floods.

Outputs: Datasets on current exposure to floods and drought, Downscaled climate predictions model datasets matched with current exposure datasets, Datasets for baselining socioeconomic scenarios.

Indicators: Number of exposure and socio-economic datasets produced at national and subnational levels, Geographic coverage of all datasets (\% of all exposed areas), Number of reports detailing data collection and summarizing information.

Outcome: Datasets used by relevant ministries to generate vulnerability assessments.

Indicators: Number of policy \& technical documents based on datasets and modeling scenarios.

2. Building national, and where relevant, local technical capacity to generate vulnerability assessments to droughts and floods.

Outputs: Technical staff acquires competence in computer modeling techniques and able to perform vulnerability analyses (VA).

Indicators: Number of technical staff trained; Average staff performance on end-of-training comprehension tests; Proportion of national-level ministries using datasets to generate vulnerability analyses or proportion of "relevant" sectors covered by analyses at national level (Note: project would need to define “all relevant ministries” or “all relevant sectors” in order to determine the proportion actually using the datasets); Proportion of regions or provinces using datasets to generate vulnerability analyses.

Outcome: Policymakers and other key stakeholders are familiarized with VA's; Results used to set priority areas for investment across agencies, sectors, and geographic levels. 
Indicators: Number of policy \& technical documents incorporating results from VA's, Proportion of government investment/program documents using results from VA's as a priority-setting or screening tool.

3. Build institutional framework and mechanisms to support adaptation and adaptive capacity.

a. Legal framework for REDD+ activities (c.f. Greiber, 2009) that provide both mitigation benefits and increased adaptive capacity.

Output: Laws that clarify the bundle of property rights to forest resources and at forest margins; laws specifying who has rights to carbon stored in forests and forest margins and procedures to transfer carbon rights both domestically and internationally; regulations and guidelines developed on carbon contract terms; dispute resolution mechanisms established; legal "literacy" programs and dissemination strategies developed and implemented.

Indicators: Number of laws and regulations created or amended to clarify land and carbon property rights; existence of a dispute resolution mechanism; number of materials (presentations, briefs, papers) developed for legal literacy programs, number of people participating in legal literacy programs.

Outcome: Reduced transactions costs for individuals and community groups to access REDD+ financing, broad-based participation in such projects and increased adaptive capacity for participants.

Indicators: Number of individuals and community groups participating in REDD+ financed projects; average number of days and money spent in project preparation; total value of projects and value per participant; \% reduction in production variability from forest-based activities and/or farm production at the forest margins, for participants versus nonparticipants.

b. Information dissemination.

Output: Climate change-related information on increased health and property hazards and response recommendations communicated; climate change-relevant information included in rural extension materials.

Indicators: Number of early warning and health hazards dissemination outlets, by type of outlet (e.g. radio, newspaper, website), geographic coverage, level of disaggregation of 
system information (e.g. province-specific or district-specific); \% languages used in dissemination materials of total number of languages spoken in country; number of extension materials containing climate change-relevant materials; \% change in government budget allocations towards climate change information dissemination.

Outcome: People, firms and government staff at all levels are prepared for climate shocks, and have the resources and capacity to respond to climate shocks, limiting damages to persons and to personal property.

Indicators: \% reduction in property damage; \% reduction in income variability; \% reduction in mortality and in disease prevalence for diseases related to weather patterns (e.g. malaria, dengue).

4. Invest in projects that directly support adaptation and improve adaptive capacity.

a. Public investment in in-situ and ex-situ seed banks.

Outputs: Wide range of seed varieties developed, documented and made available in the market, as needed.

Indicators: \% increase in the number of seed varieties held ex-situ and maintained in-situ; Documentation of seed varieties and their characteristics; Documentation of procedures and partnerships created to transfer seeds either directly to farmers or to market traders; \% increase in number of seed varieties available in rural markets.

Outcomes: Farmer's have access to, and utilize, wide range of seed varieties both to improve performance in the face of climate shocks in the short-term and to successfully adapt to climate change in the long term; greater and more stable production leading to greater food security in rural and urban areas.

Indicators: Number of climate resistant seed varieties available in the market ("market" to be defined), \% increase in use of climate resilient seed varieties; \% crop yield improvement in years of climate extremes; \% greater performance in average crop yields; \% decrease in proportion of rural and urban populations malnourished (acknowledging difficulty in attribution for the latter indicator). 
b. Project to improve ability of energy facilities to withstand climate shocks.

Outputs: Energy facilities built or retrofitted to withstand greater range of climate shocks.

Indicators: Number of facilities built or retrofitted under project; \% of total capacity built or retrofitted by type of facility and by “threat” level identified in vulnerability analyses.

Outcomes: Energy facilities able to continue operating and providing energy to all customers to a wider range of climate extremes.

Indicators: \% decrease in monetary damages to energy facilities due to climate extremes (adjusted for degree, or extent, of climate shock); \% decrease in customers losing access to energy due to climate shock-induced power failures.

In all four stages, the long-term overall impacts are to increase resilience to climate change through adaptation activities and pursue a low carbon-emissions growth strategy consistent with overall economic development goals. Earlier stages are comprised of activities that generate intermediate outputs that can be clearly linked to these ultimate impacts through a "theory of change”. For instance, following the theory of evidence-based policymaking for improved efficiency and effectiveness, data collection and model-building provide the intermediate "outcome” that government staff use data and models in policy work, and this intermediate outcome is used as an input, along with increased technical capacity to generate knowledge using data and models, in order to generate knowledge necessary to undertake priority-setting or to design screening mechanisms for resource allocation and public investment decisions. These outcomes are then inputs into institutional capacity building and reform and into implementation of concrete investments. And, the outcome of strengthened institutional capacity building is also an input into the implementation of concrete investments. So, even with projects that focus on the early stages, outcomes should be indentified within the larger "theory of change” in which project outcomes will be embedded.

\section{Indicators for Examining Projects Related to Mitigation}

The Intergovernmental Panel on Climate Change (IPCC) Fourth Assessment Report (AR4) states, with very high confidence, that the observed changes in global climate are very likely due to the increase in anthropogenic greenhouse gas (GHG) concentrations. Human activities, such as the burning of fossil fuels, the conversion of forests into agricultural land, and the 
intensification of agricultural practices, have substantially increased the level of global GHG emissions since the Industrial Revolution. In fact, if the world continues on this "business as usual" path, global emissions are projected to increase by nearly 70\% between now and 2050. To reduce the likelihood of experiencing temperature increases between 2.5-7 degrees $\mathrm{C}$ abovepreindustrial levels by the end of the century, the world must act now to reduce greenhouse gas emissions significantly. This process is concerned with the implementation of policies to reduce GHG emissions and enhance sinks (IPCC, 2007).

Mitigation interventions can take a number of forms that align with the typology discussed previously. At one end of the spectrum, pure mitigation projects may curb emissions by replacing an old, carbon intensive technology with a clean technology or reforesting an area to sequester carbon if such investments would not have been made otherwise (e.g. the high carbon-emitting technology would be chosen again for replacement, without incentives to adopt a low-carbon emitting alternative). The effectiveness of these projects tends to be measured by the total amount of emissions reductions attributable to the intervention. Falling in the middle of the spectrum are mitigation interventions that obtain emissions reductions while also delivering economic development benefits. These are sometimes referred to as "no regrets" projects if the emission reduction received under the project is a byproduct of initiatives that a country would have pursued in absence of climate change. Many of the IDB's energy efficiency or transportation improvement projects may be considered "no regrets" in the sense that they are good for development and deliver mitigation benefits; thus, these are either serendipitous or mixed mitigation/development projects discussed above.

Assessing the effectiveness, in terms of emissions reductions, for these types of interventions is challenging since it is often difficult to establish a counterfactual emissions scenario against which post-project emissions levels can be compared. The World Bank also notes "no regrets in the future" projects, which consist of actions that take into account the potential regrets stemming from potential future carbon taxes, emissions caps or other related regulations associated with high-carbon technologies (de la Torre, Fajnzylber, Nash, 2009). By adopting an "early-mover" strategy, countries may be able to benefit to a larger extent from international financing mechanisms that help with the transition to low-carbon technologies. However, because there is much risk associated with these types of financial agreements countries may be wiser to stick with no-regrets mitigation activities in the short term. 
Before advancing to a discussion of the stages of mitigation interventions it is helpful to expound on the prior point regarding international mechanisms designed to reduce global emissions. The first of these mechanisms to be discussed is the Kyoto Protocol. With the signing of the agreement in 1997, 37 industrialized (Annex I) countries committed themselves to reductions in GHG emissions while the remaining signatories (non-Annex I countries), who ratified the protocol, have hortatory responsibilities. The treaty was unique in that it set binding targets for reducing GHGs emissions. To help guide industrialized countries with their emissions reductions commitments, the United Nations Framework Convention on Climate Change (UNFCCC) provided a set guidelines to be used by Annex I countries to establish national-level inventories of GHG emissions, which are submitted on annual basis. The development of GHG inventories is important to mitigation interventions because they allow countries to establish a reference point against which they can track general trends and start to analyze the temporal and cross sectional patterns in emissions. At the project level, the concept of a baseline inventory of emissions is critical to assessing effectiveness in that it provides a reference point from which a counterfactual scenario can be built and compared with post-project emissions levels to determine impact.

Under the Kyoto Protocol, other flexible mechanisms were also introduced to help industrialized countries achieve their emission reduction targets while limiting the effects on their own economies. These included: i) emissions trading; ii) Clean development Mechanism (CDM); and, iii) Joint Implementation. Of these mechanisms, the CDM is unique in that it provides a standardized emissions offset instrument, known as certified emissions reductions (CERs) to industrialized countries implementing sustainable development projects in non-Annex I countries. To be eligible for CER credit, applicants must be able to demonstrate additionality, or the idea that a project reduces emissions more than what would have happened otherwise. While establishing additionality is most likely beyond the scope of most IDB-financed projects, the evaluation methodology and indicators developed under the CDM process are promising for assessing mitigation effectiveness at the project level.

The final climate agreement discussed here, the 2007 Bali Action Plan (BAP), was primarily responsible for setting a course of action for a binding global climate agreement in 2009 at Copenhagen. Although a global agreement remains elusive, the BAP did introduce key language concerning mitigation commitments and actions in developing countries, as well as 
nationally appropriate mitigation actions in developing countries that were measurable, reportable and verifiable. These terms, often referred to as MRV, are important because a future climate agreement is likely to require countries to comply with MRV in order to have their mitigation achievements recognized. The IPCC has devised three "tiers" for the purposes of monitoring emissions reductions, with higher tiers corresponding to more data intensive methodologies. Tier 1 requires quantifiable data on activities, and then uses IPCC default values to determine the emissions reductions from those activities. Tier 2 requires more country-specific information on emissions from activities, from which country-specific emissions can be modeled. Tier 3 approaches generally require actual monitoring of emissions reductions. The use of default values is particularly important to "land use and land use change” (LULUC) projects, since directly measuring emissions is very costly. As with additionality, establishing MRV methodologies for most IDB projects will probably not be necessary, but again, this literature is developing a number of indicators for different types of projects, and thus will provide IDB project developers with a good starting point.

\subsection{Stages of Mitigation Projects and Indicators}

With the terminology and some of the international mechanisms introduced, we now move to a discussion of the stages of projects leading to an increased ability to mitigate as noted in Figure 1. Differing from adaptation, mitigation tends to be much less affected by the uncertainty associated with future climate outcomes. However, mitigation planning is subject to the uncertainty caused by the absence of a global agreement on climate change (as well as a current agreement which is set to expire in 2012). Because developing countries are not committed to emissions reductions under the Kyoto Protocol they are also not required to submit national GHG inventories, which means the incentive to develop the institutional capacity for measuring and reporting emissions may well be sub-optimal.

However, there is still an active voluntary carbon market that appears relatively robust and also dedicated mitigation funding, e.g. through the Climate Investment Funds, which should still provide incentives to develop the necessary capacity. The importance of national-level emissions baselines will be crucial for developing a portfolio of low-carbon projects and participating in global carbon markets and funds, as well as assessing overall mitigation effectiveness. Given these points, the likely entry point for early mitigation projects will be the development of institutional capacity to monitor and track GHG emissions. Once methodologies 
for inventorying GHG emissions are in place and data has been collected, they can then be analyzed to determine which sectors or regions are ripe for low-carbon interventions. Once a country has developed a foundation for tracking emissions and has a thorough understanding of sectoral emissions, the next phase will likely be to develop a portfolio of priority projects or programs based on the initial data collection. Ranking projects in terms of cost-effectiveness, and whether they are no regrets or not, may help countries determine the appropriate phasing of projects.

The next stage is institutional capacity building. One of the first steps is often the development of a national mitigation agenda, which may be linked with the UNFCCC process of “Nationally Appropriate Mitigation Actions” (NAMA) document in order to streamline access to international mitigation funds. This may further require changes in the legal and regulatory framework - the enabling environment - for effective participation in global carbon markets and funds.

Many current climate change project proposals, particularly policy-based loans, would benefit enormously by disaggregating the type of institutional capacity on which a project focuses and more clearly articulating what measures will be addressed in order to create an enabling environment. For example, with respect to projects aimed at addressing the legal framework, concrete outputs might include regulations related to energy efficiency for buildings and homes combined with development of an enforcement strategy, drafting efficiency standards for cars, laws assigning property rights to carbon, and the development of a regulatory securities framework for engaging in carbon markets. In terms of institutions to disseminate information, examples would include capacity and resources to develop public awareness campaigns to increase the use of energy efficient lighting in residential and business spaces; or the promotion of low-carbon transportation options, such as rapid transit buses or bicycles. Any of these is better than simply "institutional capacity building for creating an enabling environment”, or “information on climate change broadly disseminated to all relevant stakeholders", for instance.

Operationalizing actions to support mitigation is the final stage. Since so many activities across all sectors generate GHGs, or alternatively, can sequester carbon to reduce emissions, it is impossible to cover all but a few examples, which we do in detail below. On the other hand, at least conceptually, the outcome indicator is simple. In nearly all cases, the primary outcome of a climate change mitigation project is reduced GHGs, and the key indicator is actual reductions in 
such emissions. However, as we shall see below, actually measuring GHG emissions is often very costly, and so other methods are used, including sampling, modeling and relying on default values for emissions reductions developed by the IPCC. In most cases, project developers should consult the UNFCCC website to obtain information on methodologies currently being used for different projects under the $\mathrm{CDM}^{7}$.

\subsection{Developing Mitigation Indicators and some Examples from Current Projects}

In this subsection, we present details from projects currently being funded under the Clean Development Mechanism of the Kyoto protocol in a number of different sectors. As with adaptation, determining baselines and counterfactuals (what would happen over time if the project was not undertaken) is very important. Unlike adaptation projects to date, however, far more work has been done on developing output and outcome indicators. Because of substantial work on output and outcome indicators has already been done, in this section we instead focus here on the identification of baselines and the construction of counterfactuals.

1. Factory Energy Efficiency Improvement in Compressed Air Demand in Mexico.

The program's objective is the implementation of energy efficiency program to reduce demand of compressed air in the manufacturing process. The output is energy efficiency program implementation, the outcome is reduced demand for compressed air and consequently lower GHG emissions, and the (very broad) impact is reduced the pace of climate change due to anthropogenic GHG emissions.

Baseline Identification -Continuation of current situation of energy consumption with current compressed air equipment installed on-site that are in compliance with local regulation.

Baseline Emissions -Based on sum of actual electricity consumption by participating facilities, and trend increases in consumption. This data is then combined with scientific formulas and efficiency factors for calculating $\mathrm{CO}_{2}$ emissions.

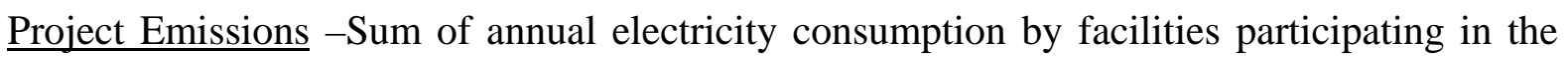
energy efficiency program; as above, this information is then combined with scientific formulas and efficiency factors to arrive at $\mathrm{CO}_{2}$ emissions under the project.

\footnotetext{
${ }^{7}$ http://cdm.unfccc.int/methodologies/index.html
} 
2. Gas Fuel Switch Project, Brazil.

Project activities focused on the conversion of 48 different types of equipment. Conversion is related to adaptation and modifications, allowing the use of natural gas instead of fuel oil, liquefied petroleum gas, or electricity.

Baseline Identification: $\mathrm{CO}_{2}$ emissions associated with fuel oil and LPG transports by truck in the baseline were determined based on appropriately selected transport distances and truck capacities.

Estimates of future fuel consumption are used for the ex-ante determination of expected project and baseline emissions.

Baseline Emissions: Emissions based on the efficiency of the current fuel oil and LPG boilers using fuel oil and LPG, respectively (measured ex-ante) combined with estimates of future fuel consumption.

Project Emissions: These are determined based on the amount of fuel oil and LPG displaced by natural gas. The amount of this fuel displaced is calculated from the natural gas consumption (monitored ex-post), the efficiency of natural gas boilers and furnaces (monitored ex-post). Emissions from five sources listed below were calculated:

- $\mathrm{CO}_{2}$ from combustion of natural gas and fuel oil

- Methane from combustion of natural gas and fuel oil

- Nitrous oxide from combustion of natural gas and fuel oil

- Fugitive $\mathrm{CH}_{4}$ emissions associated with natural gas production and distribution

- $\mathrm{CO}_{2}$ from transportation of fuel oil and LPG

The above information was then combined with measures of changes in natural gas consumption, obtained through gas company receipts and field instruments.

3. AWMS Methane Recovery Project in Baja California, Mexico.

The purpose of this project is to mitigate and recover animal effluent related GHGs by replacing open air lagoons with covered lagoon cells, creating ambient temperature anaerobic digesters. Other expected environmental benefits include improved water quality and reduced odor. 
Baseline Identification: - Given the high costs of converting open air lagoons into covered lagoon cells, and given current and likely future government regulations, project developers consider that continued use of open air lagoons would persist in the absence of the project.

Baseline Emissions: According to the project document: "The amount of methane that would be emitted to the atmosphere in the absence of the project activity can be estimated by referring to Section 4.2.5 of the Revised 1996 IPCC Guidelines for National GHG Inventories.” In other words, project developers rely on emissions factor equations already developed under the IPCC, using open anaerobic lagoon plus actual data on composition of livestock as the baseline.

Project Emissions: Actual Methane $\left(\mathrm{CH}_{4}\right)$ and $\mathrm{CO}_{2}$ emissions will be continuously monitored using a bio-gas meter.

4. Reforestation Project in southern Nicaragua.

The project area is 813 ha of former pasture land, with teak and native wood species in Southern Nicaragua. Reforestation activities will generate sustainable wood supplies, reduced pressure on natural forests, and also serve as a carbon sink.

Baseline Identification: - Current use as grasslands is considered to also be future land use for purposes of constructing the baseline.

Baseline Emissions: Given current use as grazing lands, baseline emissions (here, emissions reductions through increasing carbon stored above and below-ground) would essentially be zero (no increases in carbon stocks when lands remain as un-reforested grazing lands).

Project Emissions: Project emissions are measured based on random sampling of plots within the project area, and then applying default allometric equations to estimate increases in above and below-ground biomass due to reforestation activities.

The stratification strategy is quite sophisticated. In particular, parameters for initial stratification are tree species (native species and teak) and planting year (2003 to 2006). In year 4 after plantation the stratification is refined with strata that represent the growth conditions. These are mapped based on a grid of geo-referenced systematically distributed circular temporary sample plots of $100 \mathrm{~m}^{2}$ with a distance of $50 \mathrm{~m}$ between every plot. In each plot diameter at breast height (DBH) of every tree is measured. With an allometric 
formula total volume of the tree is calculated as a function of DBH. The average volume of each plot is then assigned to a growth class. With the help of a GIS computer program with interpolation functionality a growth map with homogeneous growth conditions is produced.

Leakage: According to the methodology, three types of leakage need to be assessed if there are displaced activities due to the project activity:

- Area under cropland displaced

- Number of domesticated grazing animals displaced

- Time-average number of domesticated roaming animals displaced

In this project, the project developers determined that none of these leakages was important, since landowner participants slaughtered most animals, though some were also sold (so some leakage in terms of animals displaced.

\section{Potential Pitfalls and "Indicators" to Avoid}

As discussed in the introduction, developing SMART indicators means developing indicators that are Specific, Measurable, Achievable, Relevant and Timely. Here, we discuss these concepts and where potential problems can occur.

\subsection{Specific}

The major problem here is that project developers often use vague terms without any hint of how such terms might be operationalized in the specific context, e.g. "widely shared”, "appropriate”, "relevant”, “are engaged in”, “understand”, etc. Another problem that often arises is that project managers specify multi-dimensional indices and not indicators, often with no apparent weighting or aggregation formula to actually construct the index, no units, and very often, using very vague language to identify what components of the index might actually look like. Two examples below illustrate this problem:

1. Evidence of coordinated approach between ministries/departments to address crosssectoral forest-related policy, planning, or practice issues [Proposed indicator for the Forest Investment Program of the CIF]

2. Knowledge of hazards, vulnerability, risks and risk reduction actions (including indigenous knowledge and coping strategies) within the community is sufficient for 
effective action by community (alone and in collaboration). [Taken from the Benfield Disaster Risk Resilience Matrix]

In the first example, someone attempting to construct this indicator will have to figure out what constitutes "evidence", and will then have to determine how to aggregate "evidence" across numerous ministries and departments and over three different subject dimensions. What if "evidence" shows coordination amongst the Ministry of Forestry and the Ministry of the Environment, but no links with the Ministry of Agriculture, Livestock and Fisheries, and weak links with the Meteorological Services? What if there is evidence of coordination amongst agencies for policy but not planning or practice issues? Who decides the "weight" assigned to each bit of evidence (is all "evidence" equally important, and thus simply tallied up against a theoretical "maximum" coordination)? What, specifically, constitutes evidence and how is the evidence itself to be weighted? In short, the "indicator" has many different components which is a good indication that it is not specific, and has no unit of measurement since the criteria for constructing the indicator is "evidence" - a vague term in this context.

In the second example, the person constructing the index will have to determine what is "sufficient knowledge for effective actions", a very vague expression. And, then the person will again have to aggregate information on "sufficient knowledge" for each of the subjects (hazards, vulnerability, risks and risk reduction actions), again by likely applying an implicit weighting function to these separate pieces of information. Then, the person will need to determine if knowledge is sufficient to act alone and in collaboration. It is unclear what the proponents of the indicator mean by "alone and in collaboration"; in collaboration with whom? Does one assess whether knowledge possessed by the people is sufficient to act alone and then again assess whether the same knowledge is sufficient to act in collaboration with other family members? Neighbors? Local government officials? NGO's?

Before moving on, it is worth noting that indices (or "composite indicators") can be helpful in aggregating multiple dimensions of a single output or outcome, but the weighting and aggregation process must be carefully thought through, and in any case, indicators of each dimension still require individual measurement and so each must be SMART. For instance, the IDB's Indicators for Disaster Risk and Risk Management (Cardona, 2007) carefully develops and documents the weighting and aggregation process for a number of indices capturing four aspects of disaster risk and management. For instance, the "Risk Management Index" (RMI) is 
comprised of four public policy dimensions, each of which has six associated indicators. The RMI indicators are all expert subjective assessments gathered using "fuzzy" linguistic categories that are assigned a number ranging from 1-5, and aggregation is performed using a fuzzy algorithm. On the other hand, the Local Disaster index uses objective measures such as the number of deaths or persons affected by disaster, and applies a different weighting algorithm. The point to note is that each of the indicators is available individually and also that there is a detailed explanation of the methodology used to weight and aggregate information to produce the indices.

Additionally, the Food and Agriculture Organization has produced a number of GISbased indices capturing soil and water degradation and deforestation and degraded forest land; the most recent version, GLADIS, still being in "beta" form. These indices may be useful in determining current adaptive capacity and in measuring current pressures on the natural resource base as reflected in the trend variables ${ }^{8}$; and certain indices have been proposed as indicators under the CIF Forest Investment Program Framework. As with the IDB's indices for disaster, GLADIS documentation presents a detailed description of the methodology used for developing the indices, including theoretical motivation for the weighting functions used. To summarize, project developers should make a clear distinction between single-dimension “indicators” versus indices that are comprised of multiple indicators. In most cases, the single-dimension indicators will be preferred, unless the project is following already developed and reviewed methodologies to construct indices, or will develop such a methodology themselves.

\subsection{Measurable}

Oftentimes, indicators that are not specific are also not measurable. Additionally, a wide range of "quality" or subjective opinion indicators suffer from lack of measurability, as do indicators that are based on feelings. For opinion-based indicators, it is often very difficult to ensure that the questions to elicit information about the indicator are "anchored", meaning that all respondents perceive the question similarly and/or that the "universe" over which they are forming opinions is the same for all respondents. As an example, a wealthy urban person will anchor questions regarding quality of education on their own range of knowledge and experience, which will likely differ from the anchor and the range of experience used to assess quality by a poor rural

${ }^{8}$ However, as documented in GLADIS report, these indicators are based on coarse-level data, and are best used in global comparisons, then regional. 
person. With respect to feelings, as noted by Liebmann and Pavanello (2007) in a review of the Benfield UCL Hazard Research Centre indicators for disaster risk, feelings - even specific feelings - are very difficult to measure, and in any case, often do not necessarily correlate with behavioral change (which is related to Relevant, as discussed below). This would include indicators of well-being, of vulnerability, of being empowered. Quality-based indicators, often prefaced with "degree" or "extent" generally are not measurable, at least not without a well thought-out strategy for identifying a "baseline" and how change from that baseline can be quantified to capture “extent” or “degree”. Below, we provide four examples.

1. Women and marginalized groups are empowered to claim their rights to land (Care Community-Based Adaptation Indicator)

2. Shared vision of a prepared and resilient community (Benfield Disaster Risk Resilience Matrix)

3. Informed, realistic attitudes toward risk and risk management (Benfield Disaster Risk Resilience Matrix)

4. People feel justifiably confident about their safety and capacities of self-reliance (Benfield Disaster Risk Resilience Matrix)

It should be very clear that, with no further attempt to specify baselines or methodologies to measure the indicators provided above, they are simply not measurable. Even where the concepts the indicators intend to measure are relatively more specific - e.g. empowered, shared vision - it is very unclear how one would go about actually measuring such concepts, including establishing a baseline. Indicators three and four are even worse, as they not only require measuring "attitudes" and "confidence", but also whether or not such attitudes are realistic (according to whom?) or justifiable (again, according to whom?).

For project management purposes, it is likely that making qualitative assessments of the above indicators can be useful for project planning and fine-tuning during the project life-cycle. Trying to actually measure such indicators, in conjunction with project beneficiaries, may also lead to the development of measurable criteria that all stakeholders agree are "indicators" of the indicators proposed above. However, because they are not measurable at the outset of the project, they are poor indicators for ensuring evaluability of development effectiveness. 


\subsection{Achievable}

Some indicators actually may be specific and measurable, but simply not achievable. For instance, determining the number of infractions of forest regulations that were subsequently subject to fine is specific and measurable, but likely only measurable at great cost. Another example is provided under the CIF; many donors would like to see indicators highly disaggregated - men, women, boys, girls, marginalized or poor, indigenous, etc., but the sample size required to generate meaningful information at this level of disaggregation is likely to be prohibitively expensive for many projects.

\subsection{Relevant}

The "relevance" criteria is also often inappropriately applied, and perhaps the most difficult to ensure. To be relevant, indicators need to be shown to actually reflect the output, outcome or impact that is being addressed. While this may be trivial for many outputs, it becomes much more complicated as we move up to outcomes and impacts. For instance, "increased yields" has been proposed as an indicator of reduced pressure on forest resources at forest margins, which is meant to capture either the outcome of increased adaptive capacity or decreased carbon emissions through avoided deforestation. However, there is a very large body of research that shows that increasing yields does not necessarily lead to reduced expansion of arable land and/or reductions in unsustainable soil and water conservation practices, and in fact, has led to just the opposite in many cases (c.f. Angelsen \& Kaimowitz, 2001; Ewers et al., 2009). A few more examples are provided below:

1. \% of communities/households with clear titles over forest land (Forest Investment Program proposed indicator)

2. \% of households with access to pasture, forests or - other common property resources (Care Community-Based Adaptation Indicator)

These indicators may or may not be relevant in any given context, and that's why they are often poor indicators. As with agricultural intensification, each of these indicators may either be negatively or positively associated with vulnerability, resilience and adaptive capacity. For instance, there is a voluminous literature on community-based natural resource management which shows highly varying results from devolving forest land management to communities. Unfortunately, this means that whether communities have clear titles has little support in the 
literature for being a good indicator of resilience and adaptive capacity (c.f. Blaikie, 2006, and references cited therein). Therefore despite its being specific, measurable and achievable, on its own it is insufficient As a side note, this indicator only considers “clear title”, which does not necessarily capture the less formal, but often still secure, tenure rights that can also lead to sustainable forest management. The second indicator captures access to common property resources as an indicator of adaptive capacity. This too may also be highly misleading. First, commons that are overexploited often generate better and more stable returns when privatized, even if they would increase adaptive capacity and resilience if they were not overexploited (McCarthy, 2004). On the other hand, if comparison is restricted only to regions with similar agro-ecological and climate conditions, then access to a wide range of common pool resources may well increase adaptive capacity and system resilience, particularly in livestock-based economies (Niamir-Fuller, 1999). Again, the point is that a good deal of context-specific knowledge is required a priori in order to ensure that the indicator is relevant and actually captures the hoped-for outcome or impact.

Finally, we note that many quantitative indicators often perform poorly in terms of relevance, particularly when the outcome is improved quality, e.g. in technical capacity and service delivery. In these cases, it is best to carefully define the characteristics of improved quality, and base indicators on these. For instance, improved health service delivery indicators could be based on time needed to access the service and costs of services, but may also be augmented by patients' subjective assessments of quality, using linguistic scores, on additional, well-defined, characteristics both at the baseline and at the end of the project.

\subsection{Timely}

Indicators should be "timely" in the sense that information is gathered at points of time that accurately reflect what the indicator is attempting to reflect. In many mitigation projects, metering equipment that continuously monitors emissions can accurately capture annual emissions whereas if emissions were only monitored say, every 6 months, those measures might instead capture either very high or very low emissions, depending on how cyclical emissions are. Adaptation and adaptive capacity projects present a more formidable problem, since some of the most important benefits may not materialize until well after the end of the project. As discussed above, this means that project developers must define intermediate outcomes that are highly 
correlated with the realization of longer term benefits, and define SMART indicators for those intermediate outcomes.

\section{Conclusions}

The objective of this document has been to lay out some of the most important issues associated with developing indicators for assessing outputs, outcomes and impacts in climate change projects. Developing SMART indicators is necessary for all projects, but climate change projects - both adaptation and mitigation - present certain difficulties not often found in other projects. The first is that many climate change projects deliver multiple benefits, e.g. a reforestation program that delivers mitigation, adaptation and development benefits. Project developers need to keep these benefits separate to the extent possible, both to develop SMART indicators but also to highlight additionality in the project arising from these multiple benefits. Also, many benefits may only be realized after the life of the project; this means that projects must have intermediate indicators that clearly link to expected future benefits in order to facilitate assessment. This means greater emphasis on the project lifecycle than is often necessary in other projects. Not discussed above is the possibility that project members may need to reassess and update indicators as more information becomes available. This type of activity should be built into the monitoring mechanism of the project.

Especially for adaptation, the longer-term improvements in resilience are likely to be a function of many different actions being undertaken both in the private and public sectors, making attribution difficult. Developing good, specific indicators for outputs and outcomes will make attribution for assessing impacts easier down the road.

A key to developing indicators for specific IDB projects, which includes multiple components and elements of the different stages noted in Figure 1, is to maintain a long-term vision of where an individual country wants to go in terms of climate change mitigation and adaptation and carefully consider how an individual project fits within this longer-term vision. The expectation is that when the IDB engages a country in promoting a country-specific climate change strategy and agenda, it will begin by either identifying the countries longer term goals or assisting the country in developing these goals. Each project will fit into this broader vision and the indicators used in that project will carefully measure progress towards achieving that vision. 


\section{References}

Angelsen A, and D. Kaimowitz. Editors. 2001. Agricultural Technologies and Tropical Deforestation. New York: CABI Publishing in Association with CIFOR.

Blakie, P. 2006. "Is Small Really Beautiful? Community-based Natural Resource Management in Malawi and Botswana.” World Development, 34(11): 1942-1957.

Burton, I., 2004, “Climate Change and the Adaptation Deficit.” In: Fenech, A. MacIver, D., Auld, H., Bing Rong, R. and Yin, Y. Editors. Climate Change: Building the Adaptive Capacity. Meteorological Service of Canada, Environment Canada, 25-33.

Cardona, O. D. 2007. "Indicators of Disaster Risk and Risk Management: Summary Report.” Washington, DC: Inter-American Development Bank.

De la Torre, A., P. Fajnzylber, and J. Nash. 2009. Low Carbon, High Growth: Latin American Responses to Climate Change - Overview. Washington, DC: World Bank Latin America and Caribbean Studies.

Ewers, R. M., J. P.W. Scharlemann, A. Balmford, and R. E. Green. 2009. "Do Increases in Agricultural Yield Spare Land for Nature?” Global Biology. On line: doi: 10.1111/j.13652486.2009.01849.x

Greiber, T. Editor. 2009. Payments for Ecosystem Services. Legal and Institutional Frameworks. IUCN, Gland, Switzerland.

Heltberg, R., P. B. Siegel, and S. L. Jorgensen. 2009. “Addressing Human Vulnerability to Climate Change: Toward a “No-Regrets” Approach.” Global Environmental Change, 19: 8999.

IPCC (Intergovernmental Panel on Climate Change), 2007. "Summary for Policymakers.” In: Parry, M. L., Canziani, O. F., Palutikof, J. P., van der Linden, P. J. and Hanson C. E. Editors. Climate Change 2007: Impacts, Adaptation, and Vulnerability. Contribution of Working Group II to the Fourth Assessment Report of the Intergovernmental Panel on Climate Change, Cambridge University Press, Cambridge, 7-22.

Liebmann, M. and S. Pavanello. 2007. "A Critical Review of the Knowledge and Education Indicators of Community-Level Disaster Risk Management.” Benfield UCL Hazard Research Centre. Paper available at:

http://www.proventionconsortium.org/themes/default/pdfs/characteristics/LSE_characteristic s_review.pdf 
McCarthy, N. 2004. With C. Dutilly-Diane, Drabo Boureima, A. Kamara and J.-P. Vanderlinden. "Managing Resources in Erratic Environments: An Analysis of Pastoral Systems in Ethiopia, Niger and Burkina Faso.” IFPRI Research Report 135. Washington, DC: International Food Policy Research Institute.

Niamir-Fuller, M. Editor. 1999. Managing Mobility in African Rangelands: The Legitimization of Transhumance. London: Intermediate Technology Publications.

Parry, M., Evans, A., Rosegrant, M. \& Wheeler, T. 2009. Climate Change and Hunger: Responding to the Challenge. WFP, IFPRI, New York University Center on International Cooperation; Grantham Institute at Imperial College London; and Walker Institute at University of Reading. Available at:

http://www.ifpri.org/sites/default/files/publications/wfp_fightingcchunger.pdf

Parry, M.L., O. F. Canziani, J. P. Palutikof, P. J. van der Linden, C. E. Hanson. Editors. 2007. Climate Change 2007: Impacts, Adaptation and Vulnerability. Contribution of Working Group II to the Fourth Assessment Report of the Intergovernmental Panel on Climate Change. Cambridge, UK: Cambridge University Press, pp. 391-431.

Rosenzweig, C. and F. N. Tubiello. 2006. “Adaptation and Mitigation Strategies in Agriculture: An Analysis of Potential Synergies.” Mitigation and Adaptation Strategies for Global Change, 12: 855-873. 